\title{
DISCERNING MATTERS OF FUTURE IMPORTANCE IN PARAPLEGIA
}

\author{
By Sir GEORGE BEDBROOK \\ Perth, W. Australia
}

IT is now a decade since, commencing with the Editorial by Sir George Godber (I969), the Journal of Paraplegia reviewed the pre-Guttmann and Guttmann eras. in the management of paraplegia and tetraplegia.

The major issue of the next decade will be the continuing management of spinal cord paralytics. The Spinal Units of 1978 are discharging people earlier, and with better initial rehabilitation, but what of their future? Difficult as it has been to convince politicians and the medical profession in general of the better prognosis for paraplegics and tetraplegics, it is going to be even more difficult in the next decade to ensure that life, having been preserved, will remain worth while and challenging both to the person who emerges from the Spinal Unit and to the medical personnel charged with this important final responsibility of emergency (Bedbrook, 1976).

If those of us managing Spinal Units accept the initial responsibility in such. emergency as spinal paralysis and tetraplegia for the continuance of life, then logically we must also accept the responsibility for what final restoration will make life worth while, or at least we must see that opportunities exist. We must give the emergent person individuality, stimulation and security with the retention of that normal aggression and competitive spirit which we have in any social community.

Consequently, as the patient moves through the acts of what might be termed the 'Rehabilitation Play' the crescendo increases as the orchestra becomes larger. Such a rehabilitation play is of great importance to the patient and doctor and is one that immediately introduces us as doctors interested in the care of paraplegics to the final responsibility. (See Figs I and 2.)

In the birthday volume of Io years ago, I found the kernel needed to initiate and maintain the effort needed in the long-term care. The initial stimulus to management came because of a challenge accepted first by Sir Ludwig Guttmann and then by the army that followed him throughout the world. When Thompson Walker (1937) indicated that intermittent catheterisation was a failure, and thus suprapubic cystostomies were indicated, such pessimism followed that most felt, and even now do feel regretfully, that as a method of management, intermittent catheterisation was impossible and condemned it. Yet Ludwig Guttmann saw it as a challenge with his tremendous individualism and as McSweeney (1969) said: 'An inability to accept compromise', and success followed in the management of the urinary tract of a group of people where failure had been accepted as a normal course of events.

Dick (1969) said that in 1944 in Warwick in a Spinal Injuries service set up in the early part of the second world war, there was a feeling of desperation amongst staff and patients-not only in the acute care but also in concern about the longterm care. To conquer such desperation and depression the continuing challenge 


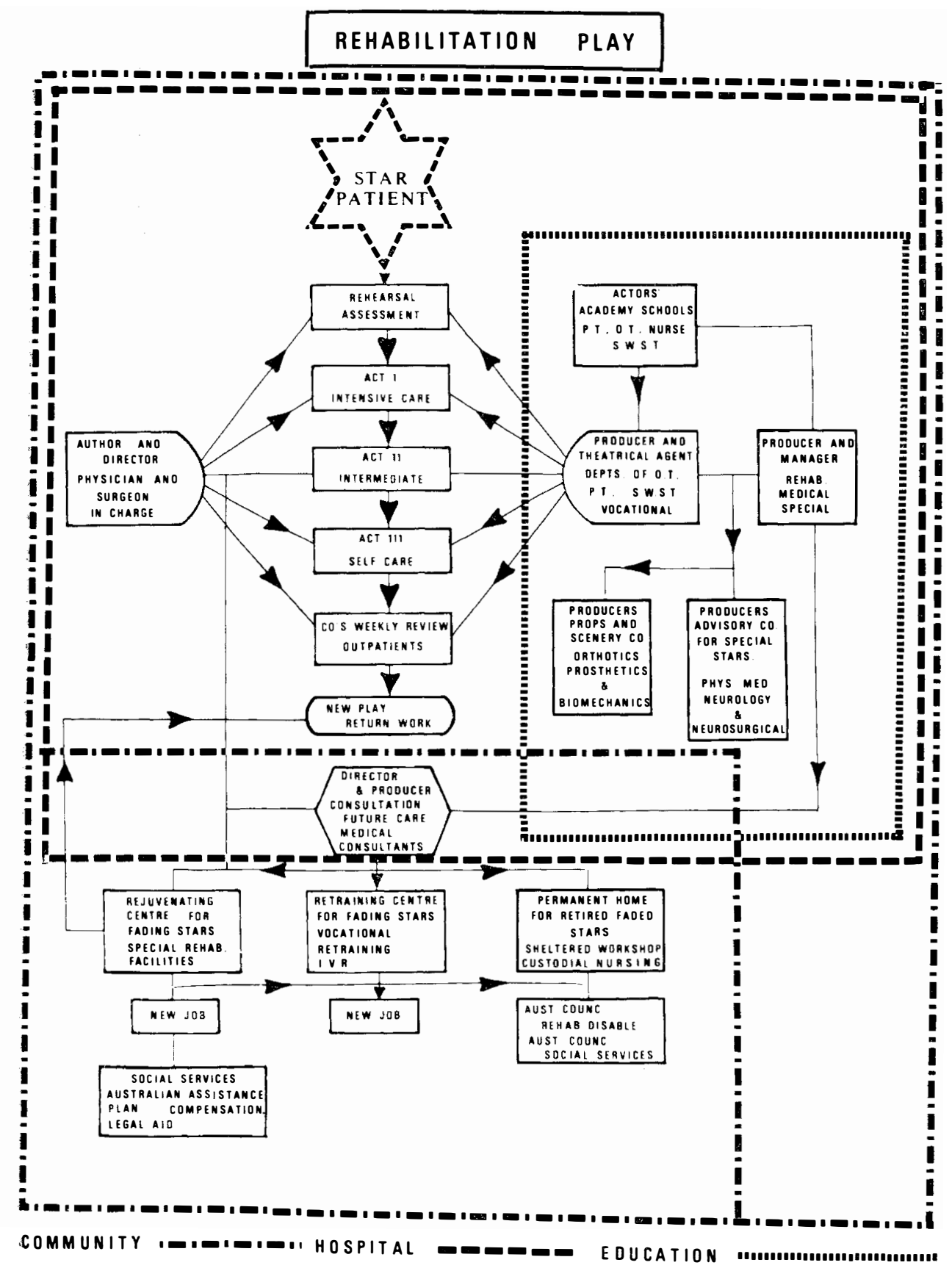

FIG. I 


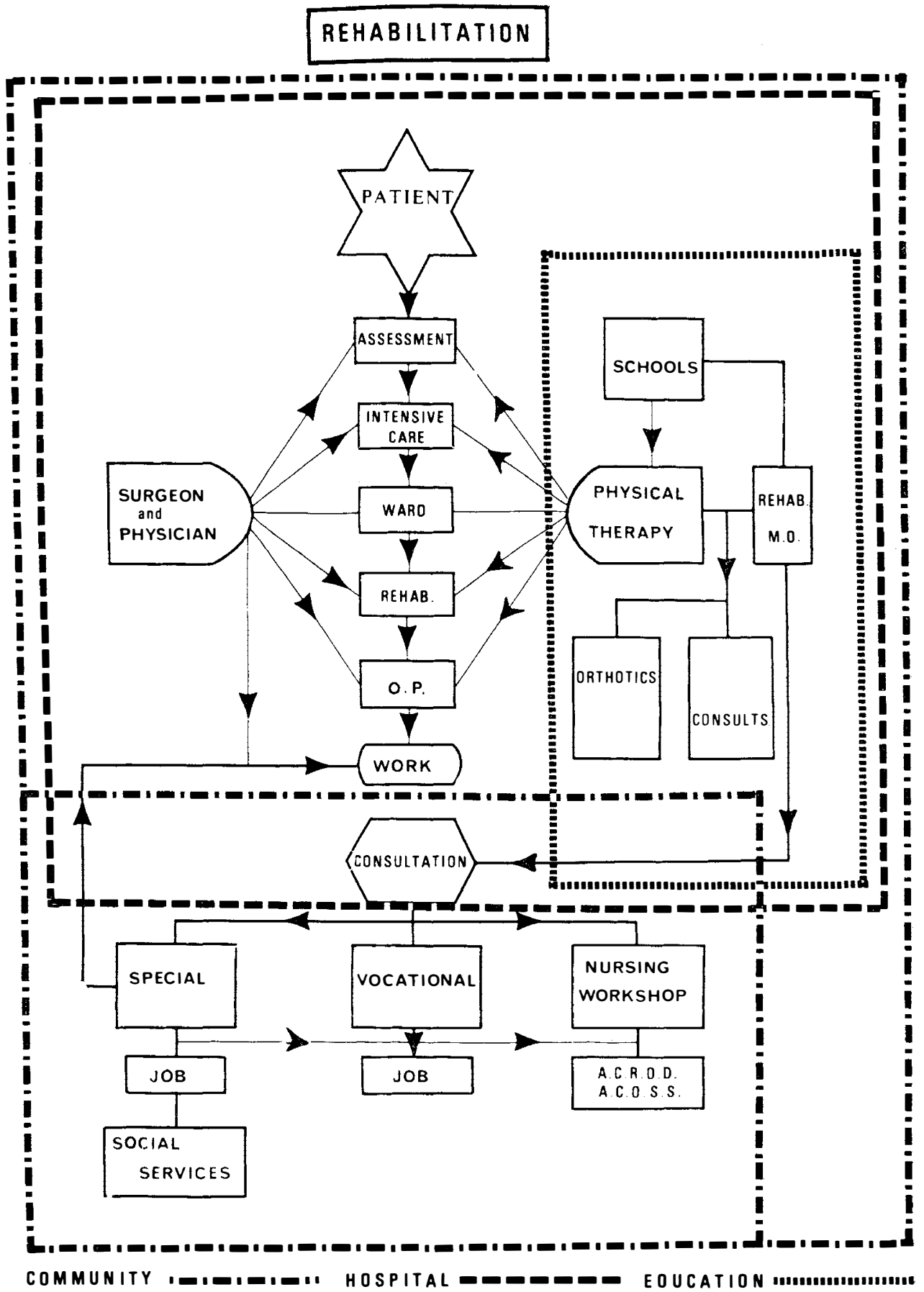

FIG. 2 
must be accepted until we see with Ludwig Guttmann the paraplegic as a disabled but healthy independent person with an independent future.

Physicians and surgeons of the future, involved in major disability including paraplegia, must have the ability to take well tested and tried (though mundane) methods and adorn them with a canvas of success and colour to be attractive, to light again and stimulate that spark which we call 'life'.

The problems of long-term care will be solved by an application therefore of the same aggressive methods of acute care to the long-term care problems. Nickel (1967) in his Robert Jones Lecture indicated that there were obstacles or preferences in the way of the majority of surgeons taking up the field of long-term care or restoration, and thus in accepting the final responsibility. These obstacles were: (I) shortage of time; (2) specialty barriers; (3) competition for acute hospital space; (4) inadequate social and financial support; (5) operating room glamour of the surgeons; (6) the technical skill of the surgeons; (7) the fear of delegation; (8) presence of severe complications; and (9) the way in which we solve complications with the application of scientific method. The latter in fact has been the area personally found to be the most difficult and initially tedious in the problem of paraplegia, but with the course of practice over a long period of time, this becomes the most interesting challenge. We must never lose sight of the compassion and feeling needed by people necessary to the management of long-term programmes for handicapped people, and thus we can echo the words of Dame Agnes Hunt (1965) who so eloquently described the influence of the late Sir Robert Jones both on herself and countless patients under her care when she said of him 'To us who are crippled he came as a refreshing breath from heaven, giving hope where hope was dead'. These words are just as true about the problems of paraplegia. Ludwig Guttmann gave paraplegics hope, but we now have the continuing problem of longterm management.

Life-long problems of paraplegics and tetraplegics must be considered by all members of the professional staff involved in the care of paraplegics in the early stages of management and the basic principles be laid down whilst the patient is still in the acute stages in the spinal unit. Fundamental principles of better longterm management are: (I) follow-up clinics attached to the Spinal Unit, or under the control of a Spinal Unit; (2) better use of nurse professionals; (3) the community activities under voluntary bodies such as Paraplegic Associations; (4) improvement in social and health legislation; and (5) education of medical personnel.

\section{Follow-up Clinics}

I.I. General review clinics must be held on a regular basis. Paraplegics and tetraplegics must see the benefit of having regular health reviews just as anyone else in the community. Outpatient attendances at the Spinal Department of Royal Perth Rehabilitation Hospital in Western Australia were 3522 in 1973-74 and jumped to 4223 in 1976-77-an increase of nearly 20 per cent. During the same period, bed utilisation dropped from 85 to 90 per cent to approximately 60 per cent, although the number of new admissions per year continued to rise to 35 per million in the population, both for traumatic and non-traumatic incidence of paraplegia. Readmissions, however, dropped from I 50 per year to about 75 per year with the average length of stay being also reduced by 50 to 60 per cent.

I.2. Urology Clinics are under the control of a trained urologist who uses all of the modern techniques of urology in reducing the number of people admitted to 
hospital. Urodynamic studies are used regularly to keep abreast in the changes in understanding of urological physiology. Urinary tract infections are treated as outpatients either in the 40 per cent who get odd infections or in the 8 per cent who get recurrent infections according to the results as enunciated by England and Pearman (1973).

In 1968 at the Spinal Unit of Royal Perth Rehabilitation Hospital a microbiologist was introduced as a member of the professional team with much revolution in thought, in management, preventive care, and now long-term care. Major reduction of urinary infection has occurred in an area where traditionally roo per cent urinary tract infection was accepted. Long-term follow-up can be maintained in an outpatient situation without regular readmission and with a minimum of complications (Pearman, 1976). Thus by regular review by the Urology Clinic and the General Clinic the numbers of readmissions for urinary cause has dropped in the past decade at Royal Perth Rehabilitation Hospital by 80 per cent and continues to be maintained at such a figure.

I.3. Pressure Clinics. In 1972 as a result of an attack on complications, a detailed study of the problem of pressure sores and their recurrence was commenced. Such pathological incidents are not just of major concern in the management of long-term paraplegia and tetraplegia but are well known to be major problems in regard to hospital admissions in general. Gingas (1973) recently reported from Montreal that in a series of admissions for paraplegia-27 to 45 per cent were for pressure sores. Fifty-one per cent of these cases came from the major teaching hospitals and in his centre alone the cost per year of looking after such problems of pressure amounted to $\mathrm{I} \cdot 4$ million Canadian dollars. It is interesting to reflect that no less a person than John Hunter in $\mathrm{I} 74 \mathrm{I}$ recognised that patients in bed were at risk in regard to tissue damage caused by uneven weight distribution. Costs of pressure sores have recently been commented upon in the Lancet. It was estimated by Fernie of the University of Strathclyde (1975) that the annual cost of care of such sores in the United Kingdom is approximately $\$ 60000000$ per year. Many of such pressure sores in non-paraplegics are the result of pressure in operating rooms for the long technical procedures of surgery.

At Royal Perth Rehabilitation Hospital in Western Australia in our Paraplegic Service alone for I97I-4I admissions for pressure occurred at an estimated cost of $\$ 89$ 860. Similarly $1972-73$ saw an increase in costs to $\$ 154452$. Many of these problems of pressure are recurrent in particular patients. Having developed a small nucleus of work in 1970-7I with a research programme by a nursing sister (Cox, 1975) 50 per cent of these recurrent admissions have now been reduced. A pressure clinic in Western Australia has now been well established from the small research group of 1972 and consists of an engineer, a trained nurse and a medical officer (see Table I).

Subsequent to the pilot study having been completed the clinic has now developed into a major hospital activity and endeavours to fit patients with wheelchairs and adequate cushioning to prevent the frictional stresses and pressure stresses. Proper attention to the distribution of pressure, as Charles Hembrow showed in Melbourne many years ago, will reduce the incidence of recurrent pressure sores. The same problem was investigated in depth in leprosy by Paul Brand and his group in Carville. In 1972 Brand reported his initial studies in regard to intermittent stress reactions of soft tissue particularly to pressure.

These showed a peculiar infiltration of polymorpho-nuclear cells associated with oedema in which there was some similarity of the hypersensitivity reaction.

Noble (1977) in a continuing research project along these lines has shown the 
TABLE I

Royal Perth (Rehabilitation) Hospital Paraplegic Service:

Treatment costs for pressure sores

\begin{tabular}{|c|c|c|c|}
\hline Year & Admissions & Patient days & Cost \\
\hline I97I & $4 \mathrm{I}$ & $\begin{array}{c}2028 \\
\text { (average 50) }\end{array}$ & $\$ 89860$ \\
\hline 1972 & 35 & $\begin{array}{c}23 \mathrm{I} 5 \\
\text { (average 6o) }\end{array}$ & $\$ 129339$ \\
\hline I973 & 46 & $\begin{array}{c}2558 \\
\text { (average 56) }\end{array}$ & $\$ 154452$ \\
\hline $1962-64$ & 40 & $\begin{array}{c}3720 \\
\text { (average 93) }\end{array}$ & $\begin{array}{r}\$ 37365 \mathrm{I} \\
\$ 58400\end{array}$ \\
\hline
\end{tabular}

importance of biomechanical and bioengineering principles in the management and prevention of pressure sores over a long-term period.

Aggressive surgery after sterilisation of decubiti will cut hospital stay by 50 per cent, and after the establishment of this regular pressure follow-up clinic the incidence of sores has also dropped by 50 per cent. Thus this follow-up clinic is a challenge both to the ancillary professional staff as well as to the plastic surgeons involved in its operation.

\section{Community Nursing}

A hospital paraplegic unit must be in close interaction with the community. This may be likened to a continuous two-ringed act, but instead of the circus ring where the two rings are separate these two rings must interact and interlock so that the hospital is part of community activity. Thus there is great emphasis on community medicine as part of the continuing restorative process. At the Royal Perth Rehabilitation Hospital Spinal Unit, community nurses were introduced through the courtesy of the voluntary body, the Paraplegic Association of Western Australia, in 1968, and have given constant and regular service since then by regular visiting of all paraplegic patients whether they be in the metropolitan area or in the country. These nurses supplement the work of the Silver Chain District Nursing Service who give constant and dedicated service to patients in their own home, particularly those who need considerable continuous nursing care. The well trained and well disciplined nurses report back to the Spinal Unit with minor problems or to general practitioners. Admission to hospital early for a few days will reduce a hospitalisation period by 80 to 90 per cent.

\section{The Development of the Voluntary Bodies}

Throughout the world there has been major development of voluntary bodies assisting in the long-term care of paraplegics and tetraplegics. Ford (1973) mentioned the early efforts in vocational workshops for the blind in Crusader days and efforts by the British Government for naval rehabilitation in the fifteenth and 
sixteenth centuries. However, it was not until the decade of 1920 and 1930 that the major societies in the western world, now serving disabled people, really developed. Rehabilitation International is now a well developed multidisciplinary body dealing with all facets of restoration. Legislation has been introduced into the many parliaments of nations whereby rehabilitation resources have been applied to any activity that would increase the health and happiness of handicapped people. In the field of paraplegia in Australia there has been the development of the voluntary bodies where Paraplegic Associations in each of the major States of Australia have made major contributions to the long-term care of paraplegics or tetraplegics.

In Western Australia, the Paraplegic/Quadriplegic Association maintains an active liaison and an active relationship with the Spinal Unit and has complemented the work of the spinal service. In I967 this voluntary body was able to acquire land adjacent to the Royal Perth Rehabilitation Hospital (see Fig. 3). Over a period of 20 years the Association provided:

3.I. A major long-term nursing care area for 65 beds which has maintained the standards as set down in the acute unit of Royal Perth Rehabilitation Hospital with the prevention of urinary tract infection, the prevention of complications for those tetraplegics and spinal paralytics of great disability, who need to have continuing long-term nursing care. Such management is supervised by a general practitioner who has become expert in the long-term care in every way, both physical and psychological, for these people. The application of acute methods of management is emphasised in this long-term nursing care area.

3.2. The Association has provided is hostel beds for the independent living

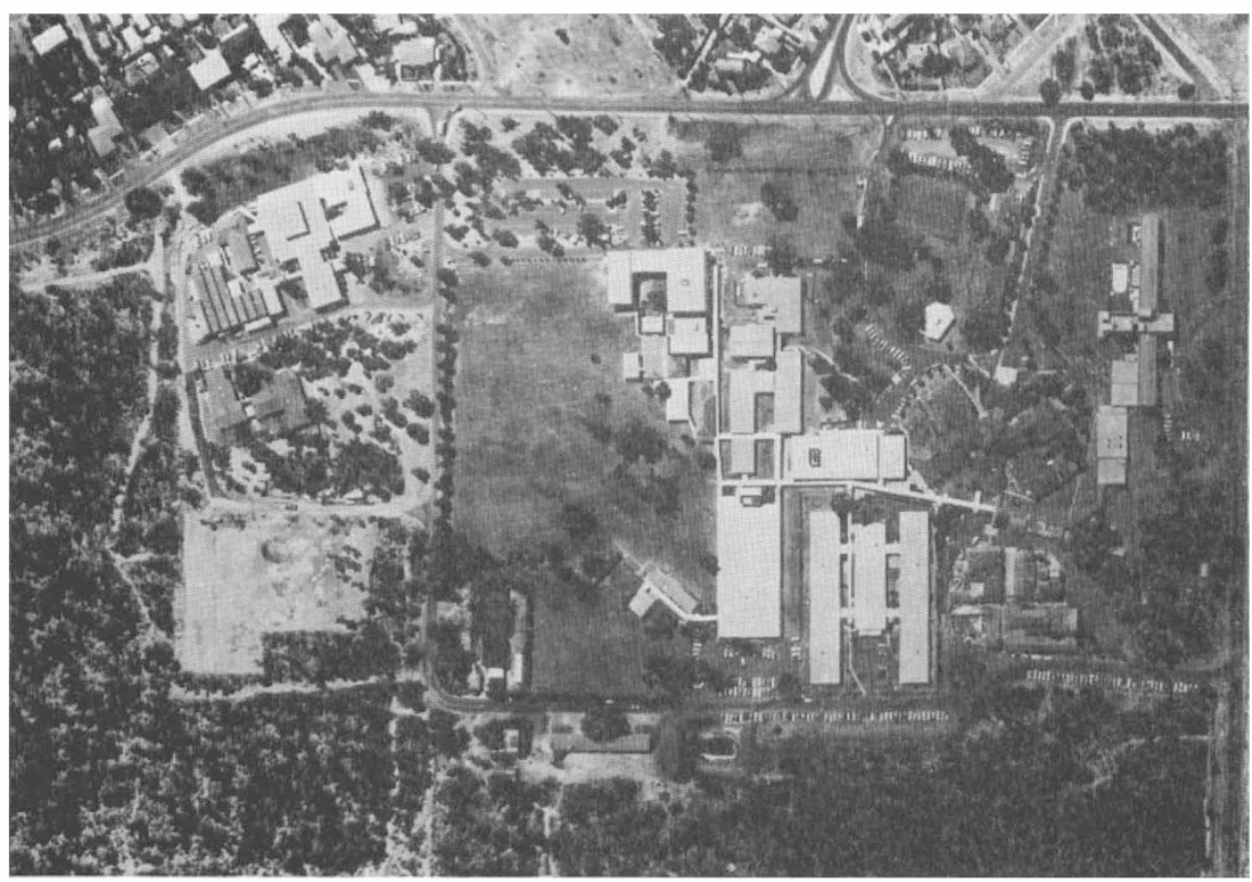

FIG. 3

Aerial photograph of Royal Perth Rehabilitation Hospital (on right) with adjacent Quadriplegic Centre (on left). 
of those paraplegics who are not able to return into the community in their own homes, or those who would normally have lived out of the metropolitan area, but for work and vocational purposes now stay in the metropolitan area.

3.3. The Paraplegic Association has established a major alternative work style and an Activity Centre. With help from the Department of Social Security an Activity Centre has been provided for those who are unable to undertake any productive work style, with a daily attendance of 60 patients from the residential complex and from outside the community. This is a multidisciplinary group under the care of a trained nursing sister and an occupational therapist. Such Activity Centres set out to stimulate the mode of life, the cultural activities and creates a challenge of doing something despite the major disability that besets these people.

The Sheltered Workshop is multidisciplinary and a major industry.

3.4. The Paraplegic Association has been responsible for the establishment of recreational areas and has a very active paraplegic and quadriplegic Sports Club.

\section{The Education of Medical and Paramedical Personnel}

If we are going to establish a continuity of care in long-term management then the importance of a team of professionals each with their own responsibility and activity in the care of paraplegia and tetraplegia cannot be overemphasised. We must look to this group of professionals more and more in the future as they will have to accept more and more activity in the long-term management. Thus the urologist with his techniques of urological care in the general community has particular emphasis in the care of the neurogenic bladder, whilst the plastic surgeon must play a major part in the management and prevention of pressure sores. The orthopaedic surgeon with his involvement in deformity must be seen to have a big responsibility.

Someone, however, must still practice the principles laid down in I944 by Ludwig Guttmann (1977-78) when he said that the whole care of paraplegia needed the services of a physician or surgeon who was willing to give up all or most of his ordinary profession to the care of paraplegics and tetraplegics. Recently Botterill (1975) indicated the need for more full-time personnel. Whilst this may be possible in some parts of the world, in Australia this will be difficult for a long time to come. The education of all medical and paramedical personnel is of tremendous importance in the long-term care of paraplegics and tetraplegics. Each member of the team must have a challenge given to him. Coordination in this final responsibility of emergency is necessary, which involves the use of the Grand Round with a panel of experts. Perhaps one of the most important advances in the field of long-term paraplegia in Perth has been the establishment of a regular meeting where a team of consultant experts meet weekly. This includes orthopaedists, radiologists, neurologists, neurosurgeons, urologists, plastic surgeons, microbiologists, medical students, nursing students as well as a greater group of medico-ancillary experts-the engineer, professional nurse, occupational therapist, sociologists, etc. Somebody has got to manage the whole of this great team and this at the present time can be any professional doctor interested and trained in this field with an ability for management.

\section{Conclusions}

Restoration of function therefore is a continuing stimulating process for traumatic paraplegics. Traumatic paraplegics show a continuing neurological 
change (Bedbrook, I976) that can be used as time proceeds. In a group of paraplegics studied at Royal Perth Rehabilitation Hospital, complete paraplegics, some 70 per cent showed long-term neurological change with appreciation of pressure in the ischial area, most of which reached a level of being valuable in the long-term process of management. Functional restoration calls for the application of the growing sciences of ergonomics, social psychology and cybernetics.

Not all management, however, is complicated. The same tools used by Sir Ludwig Guttmann many years ago, knowledge, simplicity, thoroughness, diligence, hard work, individuality are still ours to work with in the long-term management of paraplegics and offer a big challenge. Such tools are now tempered and refined in the furnaces of extended knowledge and understanding. So often in life the only cause worth while with challenge is a lost cause.

Medical care programmes have the initial impact and must be the elder statesman, but must be ready to accept change, for having started the process medicine is now responsible for the long-term follow-up, particularly in progressive or recurrent illness. The great trinity of rehabilitation is manifested in service, teaching and research. Throughout all movements of the great orchestral symphony of restoration and habilitation, repetitive practice must be emphasised to give the final result.

The key note must be 'expertise' by all members which will stimulate adventure and motivation in staff, while giving individual care and motivation to the person concerned. To paraphrase Churchill; 'We are at the end of the beginning' in the care of paraplegia and tetraplegia, but there is no ending to this task. We must apply all the lessons of the past in the long-term management of paraplegics and tetraplegics, for it is continuing application of the so-called acute methods that will give excellent long-term results to maintain a 75 per cent success rate that is common in many areas of disability. Practice by all is required over years and years of service.

\section{REFERENCES}

BEDbRook, G. M. (1975). Treatment of thoracolumbar dislocation. Clin. Orth. E Rel. Res. I12, 27-43.

Bedbrook, G. M. (I976). The final responsibility of emergency. Med. fournal of Aust. I, IO7-IIO.

Bedbrook, G. M. (1976). Injuries of the spine and spinal cord. Handbook Clin. Neurol. 25 (I), 437-466.

BEDBROOK, G. M. (1976). Late neurological observations in complete cord transections. Lecture delivered 6th Comb. Meeting of Orthopaedic Association, September.

BEDbrook, G. M. (I977). The historical theme of rehabilitation. R.A.C.S. Proceedings Rehabilitation Workshop, March 4-I I.

BotTERILl, E. H. (1975). A model for the future care of acute spinal cord injuries. Annals of the R.C.P.S., Canada, Jan.

Cox, L. (I975). Prevention of decubitus ulcers in spinal paralysis. The wheelchair patient. Perth. Para-Quad Industries, March.

Dick, T. B. S. (1969-70). Traumatic paraplegia pre-Guttmann. Paraplegia 7, I73-178.

ENGland, E. \& Pearman, J. (1973). The Urological Management of the Patient following Spinal Cord Injury. C. Thomas, Illinois.

FERNIE, G. R. \& DorNAN, J. (I975). The problems of clinical trials with new systems for preventing or healing decubiti. Conf. on Biomechanics of Tissue Viability and Clinical Applications. University of Strathclyde, Glasgow.

Ford, B. (I973). Rehabilitation: the analysis of a concept. Med. F. of Aust. I, 907-910.

GINGAS, G. (I973). Rehabilitation of the spinal cord involved-a critical study. Proc. International Symposium on Rehabilitation of the Industrially Injured, Vancouver, pp. 47-50.

GodBer, SIR G. E. (1969-7I). Sir Ludwig Guttmann. Paraplegia 7-8, I45. 
Guttmann, Sir L. (1968). New talent for the community. Address to Pan Pacific Conference in Hong Kong.

GutTMANN, Sir L. (I977-78). Total responsibility of the surgeon in the management of traumatic spinal paraplegics and tetraplegics. Paraplegia, I5, 285-292.

Hunt, Dame A. (1965). This is my Life. Wheaton \& Co., Great Britain.

McSweEney, T. (1969). Tributes to Sir Ludwig Guttmann. Paraplegia, 7-8, I67.

NiCKEL, V. (I967). Orthopaedic rehabilitation challenges and opportunities. Sir Robert Jones Lecture. New York.

Noble, P. (1977). Report on the involvement of the bioengineering division in the management of pressure sore problems within the acute and rehabilitation areas of the hospital. Unpublished.

Pearman, J. (1976). Urological follow-up of 99 spinal cord injured patients initially managed by intermittent catheterisation. British fournal of Urology, 48, 297-310.

Thomson WalkeR, Sir J. (1937). Treatment of bladder in spinal injuries in war. British fournal of Urology, 9, 217. 